\title{
Reaction behaviour of a complex containing a tungsten phosphorus triple bond with $\sigma$-acceptor compounds of group 13
}

\author{
Manfred Scheer, ${ }^{*} \dagger \dagger$ Jan Müller, $^{a}$ Gerhard Baum $^{a}$ and Marco Häser ${ }^{b}$ \\ a Institute of Inorganic Chemistry, University of Karlsruhe, D-76128 Karlsruhe, Germany \\ ${ }^{b}$ Institute of Physical Chemistry, University of Karlsruhe, D-76128 Karlsruhe, Germany
}

$\left[\mathrm{LW} \equiv \mathrm{P} \rightarrow \mathrm{GaCl}_{3}\right] 5\left[\mathrm{~L}=\mathrm{N}\left(\mathrm{CH}_{2} \mathrm{CH}_{2} \mathrm{NSiMe}_{3}\right)_{3}\right]$ is prepared by treatment of $[\mathrm{LW} \equiv \mathrm{P}]$ with $\left(\mathrm{GaCl}_{3}\right)_{2}$; decomposition of 5 in $\mathrm{CH}_{2} \mathrm{Cl}_{2}$ affords dimerisation under $\mathrm{Me}_{3} \mathrm{SiCl}$ elimination to give a cationic $\mathrm{W}_{2} \mathrm{P}_{2}$ tetrahedral complex 6; both complexes are structurally characterised.

In 1995 Cummins ${ }^{1}$ and Schrock $^{2}$ and their coworkers succeeded in the synthesis and the first structural characterisation of complexes $\mathbf{1}$ and $\mathbf{2}$, respectively, containing a metal phosphorus triple bond. Our synthetic goal, however, has been directed towards the alkoxide substituted complexes $\mathbf{3}$ where the phosphido ligand coordinates additionally to a metal pentacarbonyl fragment. ${ }^{3}$ The ${ }^{1} J_{\mathrm{WP}}$ coupling constant was observed to be 554 (3a) and $536 \mathrm{~Hz}$ (3b) for the triple bond and appeared to be in contradiction with the $138 \mathrm{~Hz}$ found for the $\mathrm{W}$ complex 2a. To shed light onto this problem we decided to synthesise 2a $\left(\mathrm{M}^{\prime}=\mathrm{W}\right)$ via the reaction of $[\mathrm{WCl}(\mathrm{L})][\mathrm{L}=$ $\left.\mathrm{N}\left(\mathrm{CH}_{2} \mathrm{CH}_{2} \mathrm{NSiMe}_{3}\right)_{3}\right]$ with $\mathrm{Li}\left[\mathrm{P}\left(\mathrm{SiMe}_{3}\right)_{2}\right]$. Subsequent reaction with $\left[\mathrm{M}^{\prime}(\mathrm{CO})_{5}(\right.$ thf $\left.)\right]$ leads to the trans-substituted complexes $4{ }^{4}$ ${ }^{31} \mathrm{P}$ NMR data $\left(\mathbf{4 a}: \delta 679.8,{ }^{1} J_{\mathrm{WP}} 426 \mathrm{~Hz} ; \mathbf{4 b}: \delta 728.1,{ }^{1} J_{\mathrm{WP}} 413\right.$ $\mathrm{Hz}$ ) combined with theoretical calculations reveal that the linear coordination of a complex fragment to the phosphido atom is responsible for a dramatic increase of the s character of the triple bond and consequently for the increase of the coupling constant. In further studies it was of interest how coupling constant and triple bond length behave by coordination of a simple $\sigma$-acceptor group. Herein we report our results of the reaction of 2a with group 13 Lewis acids.

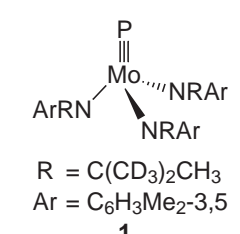

1

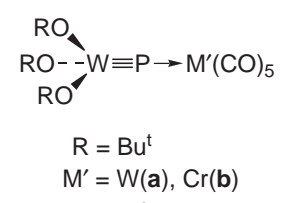

3

The reaction of $\mathbf{2 a}$ with $\mathrm{BH}_{3} \cdot \mathrm{SMe}_{2}$ only led to an insoluble solid. Elemental analysis did not indicate the formation of the expected adduct $\left[\mathrm{LW} \equiv \mathrm{P} \rightarrow \mathrm{BH}_{3}\right]$. Even following the reaction by 31P NMR only showed that the starting material disappeared but no new signal could be detected. In the reaction of $\mathbf{2 a}$ with $\mathrm{BF}_{3} \cdot \mathrm{OEt}_{2}$ in $\mathrm{CH}_{2} \mathrm{Cl}_{2}$, however, a ${ }^{31} \mathrm{P}$ NMR signal at $\delta 607\left({ }^{1} J_{\mathrm{WP}}\right.$ $478 \mathrm{~Hz}$ ) could be observed for a short time. Then the reaction mixture became black and insoluble black material precipitated.

Reaction of $2 \mathbf{a}$ with the dimer $\left[\mathrm{GaCl}_{3}\right]_{2}$ in a $2: 1$ ratio in toluene led to the isolation of a yellow crystalline compound $\mathbf{5}$, which is sparingly soluble in toluene, thf and $\mathrm{CH}_{2} \mathrm{Cl}_{2} \neq$ The ${ }^{31} \mathrm{P}\left\{{ }^{1} \mathrm{H}\right\}$ NMR spectrum of 5 reveals one signal at $\delta 366$ bearing one pair of satellites with ${ }^{1} J_{\mathrm{WP}}=712 \mathrm{~Hz}$. The high field shift as well as the considerable increase of the coupling constant is consistent with those found in 4. However, the observed coupling constant is one of the largest for these triple bond systems. Almost identical NMR data were detected in the structurally uncharacterised complex $[\mathrm{LW}=\mathrm{PMe}]^{+}-[\mathrm{OTf}]^{-}(\delta$ $339,{ }^{1} J_{\mathrm{WP}}=748 \mathrm{~Hz}$ ) synthesised by Schrock and coworkers. ${ }^{5}$

The molecular structure of $\mathbf{5}$ was established by a singlecrystal X-ray diffraction study.§ The main feature of the molecular structure of $\mathbf{5}$ is the entirely linear arrangement of the $\mathrm{N}_{\mathrm{ax}}-\mathrm{W}-\mathrm{P}-\mathrm{Ga}$ axis (Fig. 1). The $\mathrm{Cl}$ atoms of the $\mathrm{GaCl}_{3}$ group are slightly disordered. The orientations of the $\mathrm{Cl}$ atoms are slightly eclipsed to the $\mathrm{W}-\mathrm{N}(2)$ bonds, but staggered to the $\mathrm{N}(1)-\mathrm{C}(1)$ bond. The $\mathrm{W} \equiv \mathrm{P}$ bonding distance is $2.168(4) \AA$ which is only slightly longer than the bond length found in $2 \mathbf{a}(2.162 \AA)$. This indicates the replacement of almost the same amount of phosphorus $3 p$ o-contribution to the $\mathrm{W} \equiv \mathrm{P}$ bond in $2 \mathrm{a}$ by $3 \mathrm{~s}$-orbital contribution of the former lone pair of the phosphorus, produced through the coordination to a $\sigma$-acceptor such as $\mathrm{GaCl}_{3}$. This finds further support from the dramatic increase of ${ }^{1} J_{\mathrm{WP}}$. Owing to the remarkable backbonding ability of the $\mathrm{W} \equiv \mathrm{P}$ moiety to the $\mathrm{W}^{0}$ centre the triple bond length increases from $2.162(4)$ in $\mathbf{2 a}$ to $2.202(2) \AA$ in $\mathbf{4 a} .{ }^{4}$ The most significant difference in bonding distances in comparison to $\mathbf{2 a}$ occurs for the $\mathrm{N}_{\mathrm{ax}}-\mathrm{W}$ bond which is shortened by $0.10 \AA$. This is probably

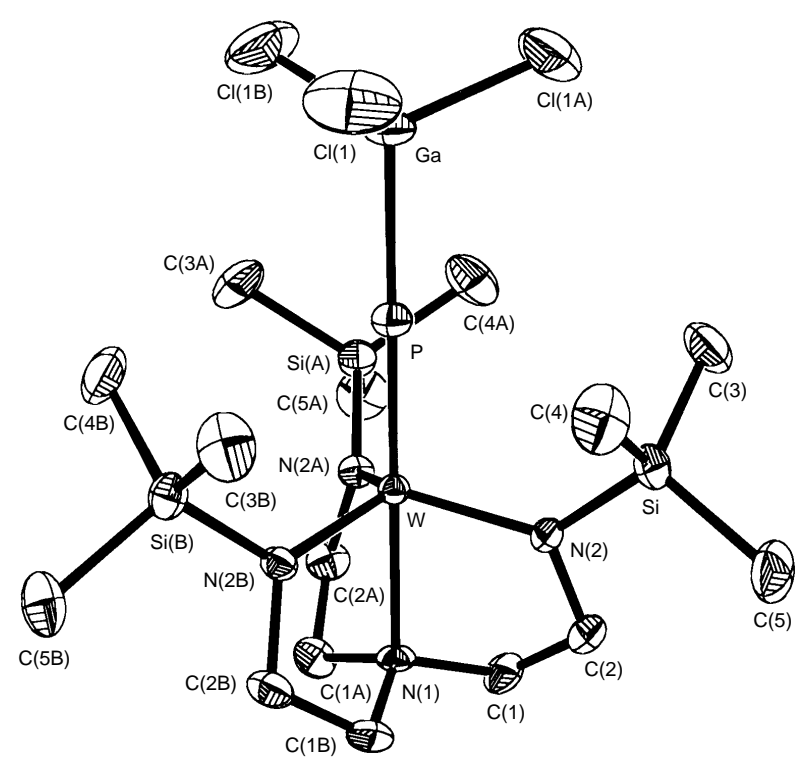

Fig. 1 Molecular structure of $\mathbf{5}$ (only one position of the $\mathrm{Cl}$ atoms is drawn for clarity). Selected bond lengths $(\AA)$ and angles $\left({ }^{\circ}\right)$ : W-P 2.168(4), P-Ga 2.335(4), W-N(1) 2.248(10), W-N(2) 1.967(3), Ga-Cl(1) 2.159(11), Ga$\mathrm{Cl}(2) 2.186(12), \quad \mathrm{N}(1)-\mathrm{W}-\mathrm{P}$ 180.0, W-P-Ga 180.0, N(1)-W-N(2) 77.52(8). 
due to a reduced electron density at the metal core which results in a higher acceptor ability of the $\mathrm{W}$ atom. The $\mathrm{Ga}-\mathrm{P}$ distance is 2.335(4) $\AA$. This is consistent for $\mathrm{Ga}-\mathrm{P}$ single bonds as found in e.g. $\mathrm{GaCl}_{3}\left(\mathrm{PMe}_{3}\right)(2.353 \AA){ }^{6}$

The structural features of 5 were modelled using the B-P86/ SVP density functional approximation. ${ }^{7}$ The structural optimisation resulted in a molecular shape best described in terms of $C_{3}$ symmetry. There is good agreement between the calculated and experimentally observed structural parameters [calc.: $d(\mathrm{~W} \equiv \mathrm{P})=2.186 \AA, d\left(\mathrm{~W}-\mathrm{N}_{\mathrm{eq}}\right)=2.007 \AA$ 的 $\mathrm{Ga})=2.335(4) \AA, \quad d(\mathrm{~W} \equiv \mathrm{P})=2.168(4) \AA, \quad d(\mathrm{~W}-$ $\left.\left.\mathrm{N}_{\text {eq }}\right)=1.967(3) \AA\right]$. The only exceptions are the calculated distances for $\mathrm{P}-\mathrm{Ga}$ and $\mathrm{W}-\mathrm{N}_{\mathrm{ax}}$, which are longer by 0.1 and 0.2 $\AA$, respectively. For the latter bond, the same effect was found in the calculated and experimental structures of $\mathbf{2 a}$ and $4 \mathbf{a} .^{4}$

Electronic energies, calculated with the B-P86/SVP (B3-LYP/ SVP) approximation, show reaction of 2a with 0.5 $\left(\mathrm{GaCl}_{3}\right)_{2}$ to be exothermic at $-68(-61) \mathrm{kJ} \mathrm{mol}^{-1}$. The same methods calculated the energies for the reaction of $\mathbf{2 a}$ with $\mathrm{BH}_{3}$.thf to be $-22(-2) \mathrm{kJ} \mathrm{mol}^{-1} \cdot{ }^{4}$ In accordance with the experimental observation the formation of a $\mathrm{BH}_{3}$ adduct seems to be less favoured in comparison with the preferred formation of the $\mathrm{GaCl}_{3}$ adduct 5.II

However, a solution of $\mathbf{5}$ in $\mathrm{CH}_{2} \mathrm{Cl}_{2}$ appears to be unstable. After a few days the yellow-brown colour of the solution disappears. Red, star shaped crystals of $\mathbf{6}$ and an amorphous solid precipitated. According to a ${ }^{31} \mathrm{P}\left\{{ }^{1} \mathrm{H}\right\}$ NMR study the $\mathrm{CH}_{2} \mathrm{Cl}_{2}$ solution contains no detectable amounts of phosphorus. The red crystalline compound was examined by X-ray diffraction, $\S$ but only a weak data set was obtained. However, it was possible to solve the structure to a reasonable degree. The structure revealed a tetrahedral $\left[\mathrm{W}_{2} \mathrm{P}_{2}\right]^{+}$moiety, where the $\mathrm{W}$ atoms are coordinated by two tren type ligands (Fig. 2). These are linked together by two $\mathrm{GaCl}_{2}$ groups which are in the former position of the $\mathrm{SiMe}_{3}$ moieties. Furthermore, all $\mathrm{SiMe}_{3}$ groups are removed and $\left[\mathrm{GaCl}_{4}\right]^{-}$and $\mathrm{Cl}^{-}$occur as counter ions. The W-P bonds are now 2.462(12) and 2.473(10) $\AA$ and the W-W bond is $2.585(2) \AA$. A related nitrido bridged tungsten dimer is $\left[\mathrm{W}_{2}\left(\eta^{5}-\mathrm{C}_{5} \mathrm{H}_{4} \mathrm{Pr}^{\mathrm{i}}\right) \mathrm{Cl}_{2}(\mu-\mathrm{NR})\left(\mu-\mathrm{C}_{2} \mathrm{Et}_{2}\right)\right]$ with an analogous $\mathrm{W}-\mathrm{W}$ distance of 2.5923(5) $\AA .8$ Obviously, in the first step of the conversion of 5 the $\mathrm{Si}-\mathrm{N}$ bond is cleaved to form the thermodynamically stable $\mathrm{SiClMe}_{3}$. The replacement by $\mathrm{GaCl}_{2}$ moieties leads to a rearrangement resulting in the formation of the $\mathrm{W}_{2} \mathrm{P}_{2}$ complex 6 .

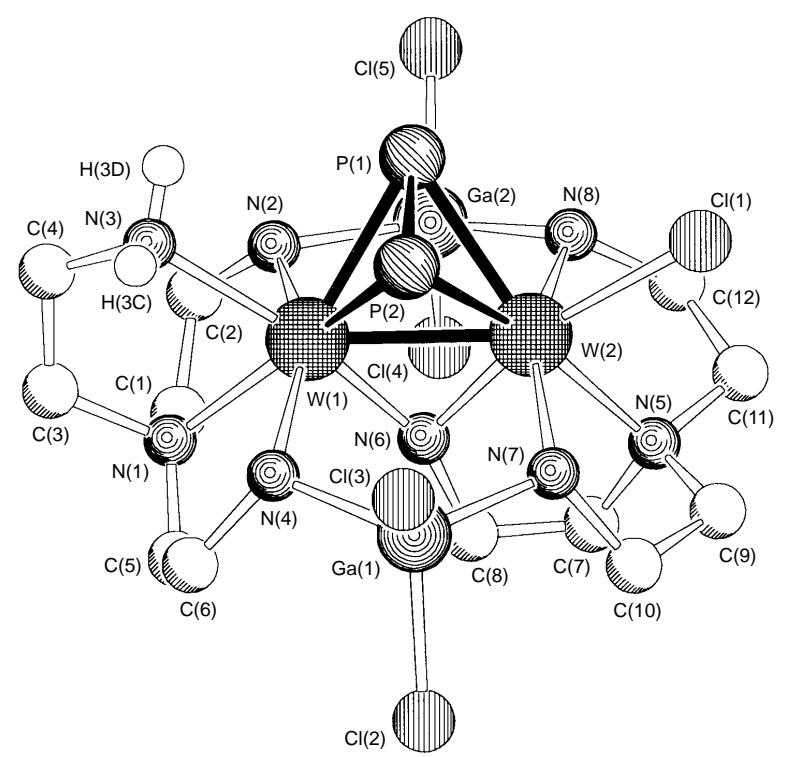

Fig. 2 Molecular structure of 6. Selected bond lengths $(\AA)$ : $P(1)-P(2)$ 2.07(2), W(1)-P(1) 2.461(12), W(1)-P(2) 2.473(10), W(2)-P(1) 2.483(11), $\mathrm{W}(2)-\mathrm{P}(2) \quad 2.498(9) ; \quad \mathrm{Cl}(1)-\mathrm{W}(2) \quad 2.464(12), \quad \mathrm{W}(1)-\mathrm{W}(2) \quad 2.585(2)$, $\mathrm{W}(1)-\mathrm{N}(6)$ 1.97(3), W(2)-N(6) 2.00(3).
The transformation of $\mathbf{5}$ into $\mathbf{6}$ could explain the instability of complexes of the type $\left[\mathrm{LW} \equiv \mathrm{P} \rightarrow \mathrm{EX}_{3}\right](\mathrm{E}=\mathrm{B}, \mathrm{Ga} ; \mathrm{X}=\mathrm{H}, \mathrm{F}$, $\mathrm{Cl}$ ). Loss of $\mathrm{SiClMe}_{3}$ or $\mathrm{SiHMe}_{3}$ decreases the steric protection of the $\mathrm{W} \equiv \mathrm{P}$ triple bond which results in arbitrary formation of higher aggregates of unknown composition. Deliberate attempts to remove $\mathrm{SiMe}_{3}$ groups may activate the $[\mathrm{LW} \equiv \mathrm{P}]$ complex with their preferred end-on reactivity to undergo side-on reactions. This is a goal for further investigations.

The authors thank the Deutsche Forschungsgemeinschaft and the Fonds der Chemischen Industrie for financial support.

\section{Notes and References}

† E-mail: mascheer@achibm6.chemie.uni-karlsruhe.de

$\ddagger$ Spectroscopic data for $5\left(\left[{ }^{2} \mathrm{H}_{8}\right]\right.$ thf $):{ }^{31} \mathrm{P}\left\{{ }^{1} \mathrm{H}\right\}$ NMR, $\delta 366, J_{\mathrm{WP}} 712 ;{ }^{1} \mathrm{H}$ NMR, $\delta 3.91\left(\mathrm{t}, 6 \mathrm{H}, \mathrm{CH}_{2}\right), 2.46\left(\mathrm{t}, 6 \mathrm{H}, \mathrm{CH}_{2}\right), 0.45\left(\mathrm{~s}, 27 \mathrm{H}, \mathrm{CH}_{3}\right) ;{ }^{13} \mathrm{C}\left\{{ }^{1} \mathrm{H}\right\}$ $\mathrm{NMR}, \delta 55.16\left(\mathrm{~s}, \mathrm{CH}_{2}\right), 52.36\left(\mathrm{~s}, \mathrm{CH}_{2}\right), 5.38\left(\mathrm{~s}, \mathrm{CH}_{3}\right)$; correct elemental analysis.

$\S$ Crystal structure analysis: 5: $\mathrm{C}_{15} \mathrm{H}_{39} \mathrm{Cl}_{3} \mathrm{GaN}_{4} \mathrm{PSi}_{3} \mathrm{~W}, M=750.66$, trigonal, space group P31c, $a=b=11.867(2), c=12.207(2) \AA, Z=2$, $U=1488.7(4) \AA^{3}, D_{\mathrm{c}}=1.675 \mathrm{Mg} \mathrm{m}^{-3}, \mu(\mathrm{Mo}-\mathrm{K} \alpha)=52.9 \mathrm{~cm}^{-1}$, $F(000)=740, T=200(2) \mathrm{K}$. A total of 4631 reflections with $7.76 \leqslant 2 \theta \leqslant$ $51.42^{\circ}$ were collected on a STOE IPDS (image plate detector system) with Mo-K $\alpha$ radiation $(0.71069 \AA)$, of which 1811 were independent $\left(R_{\text {int }}=0.0364\right)$. The 1749 reflections with $I \geqslant 2 \sigma(I)$ were used in the full least squares refinement. The structure was solved by direct methods (SHELXS-86) and standard Fourier techniques (SHELXL-93). Full matrix least squares refinement of the thermal parameters (anisotropic for all atoms except hydrogen) led to convergence with final residuals of $R_{I}=0.0189$ and $w R_{2}=0.0461$ and GOF $=1.078$ for 110 variables. Residual electron density was found to be between 0.925 and -0.441 e $\AA^{-3}$. 6: $4\left[\mathrm{C}_{45} \mathrm{H}_{95} \mathrm{Cl}_{5} \mathrm{Ga}_{2} \mathrm{~N}_{8} \mathrm{P}_{2} \mathrm{~W}_{2}\right]\left[\mathrm{GaCl}_{4}\right] \mathrm{Cl}_{3} \cdot 3 \mathrm{CH}_{2} \mathrm{Cl}_{2}, M=4681.56$, tetragonal, space group $I \overline{4}, a=b=22.059(3), c=13.185(3) \AA, U=6416(2) \AA^{3}$, $Z=2$ (for four molecules of the $\mathrm{W}_{2} \mathrm{P}_{2}$ complex), $D_{\mathrm{c}}=2.421 \mathrm{Mg} \mathrm{m}^{-3}$, $F(000)=4364, \mu(\mathrm{Mo}-\mathrm{K} \alpha)=98.24 \mathrm{~cm}^{-1}, 225$ parameters, crystal size $0.08 \times 0.04 \times 0.02 \mathrm{~mm}, T=200(2) \mathrm{K}$. A total of 6756 reflections with $3.7<$ $\theta<45^{\circ}$ were collected on a STOE IPDS with Mo-K $\alpha$ radiation $(0.71069$ $\AA), 3757$ of them were independent $\left(R_{\text {int }}=0.1825\right)$. 2867 reflections with $I \geqslant 2 \sigma(I)$ were used in the full least squares refinement. The structure was solved as above. Full matrix least squares refinement of the thermal parameters (anisotropic for all $\mathrm{W}, \mathrm{Ga}, \mathrm{P}$ and $\mathrm{Cl}$ atoms except those of the solvent $\mathrm{CH}_{2} \mathrm{Cl}_{2}$ ) led to convergence with final residuals of $w R_{2}=0.2245$ for all reflections, corresponding to a conventional $R_{l}=0.0952$ for the observed $F_{\mathrm{o}}$ data. Residual electron density was found to be between 2.839 and -1.718 e $\AA^{-3}$. CCDC $182 / 813$.

II The reaction between $\mathbf{2 a}$ and $\mathrm{BH}_{3}$.thf presumably leads to elimination of $\mathrm{HSiMe}_{3}$.

1 C. E. Laplaza, W. M. Davis and C. C. Cummins, Angew. Chem., 1995, 107, 2181; Angew. Chem., Int. Ed. Engl., 1995, 34, 2042.

2 N. C. Zanetti, R. R. Schrock and W. M. Davis, Angew. Chem., 1995, 107, 2184; Angew. Chem., Int. Ed. Engl., 1995, 34, 2044.

3 M. Scheer, K. Schuster, T. A. Budzichowski and M. H. Chisholm, W. E. Streib, J. Chem. Soc., Chem. Commun., 1995, 1671.

4 M. Scheer, J. Müller and M. Häser, Angew. Chem., 1996, 108, 2637; Angew. Chem., Int. Ed. Engl., 1996, 35, 2492.

5 N. C. Mösch-Zanetti, R. R. Schrock, W. M. Davis, K. Wanninger, S. W. Seidel and M. B. O’Donoghue, J. Am. Chem. Soc., 1997, 119, 11037.

6 J. C. Charter, G. Jugie, R. Enjalbert and J. Galy, Inorg. Chem., 1978, 7, 1248.

7 Structure optimizations were performed using the TURBOMOLE set of programs with the RI- $J$ approximation (K. Eichkorn, O. Treutler, H. Öhm, M. Häser and R. Ahlrichs, Chem. Phys. Lett., 1995, 242, 652). For definition of the B-P86 density functional, see: A. D. Becke, Phys. Rev. A, 1988, 38, 3098; J. P. Perdew, Phys. Rev. B, 1986, 33, 8822; 1986, 34 7046. The acronym SVP refers to TURBOMOLE split valence basis sets, augmented by a shell of polarization functions, see: A. Schäfer, H. Horn and R. Ahlrichs, J. Chem. Phys., 1992, 97, 2571. Quasi-relativistic pseudopotentials were used for tungsten (D. Andrae, U. Häußermann, M. Dolg, H. Stoll and H. Preuß, Theor. Chim. Acta, 1990, 77, 123; A. Bergner, M. Dolg, W. Küchle, H. Stoll and H. Preuß, Mol. Phys., 1993 , 80, 1431). The corresponding SVP basis sets optimized for W by F. Weigend, K. Eichkorn and R. Ahlrichs are unpublished.

8 M. L. Green, P. C. McGowan and P. Mountford, J. Chem. Soc., Dalton Trans., 1995, 1207.

Received in Cambridge, UK, 9th February 1998; 8/01136B 